\title{
Factors Affecting Perceived Stress in Pre-Hospital Emergency Medical Services
}

\author{
Roger Bounds
}

\author{
Northern Arizona University
}

\begin{abstract}
This study investigated the factors related to the perception of stress in EMT's and paramedics. 144 EMTs and paramedics from urban "third service" EMS providers in Texas completed a questionnaire that included several demographic questions, Speilberger's (1995) state-trait personality inventory (STPI), Sarason's (1983) social support questionnaire, and Schwarzer's (2000) general perceived self-efficacy scale. Six of the eight SPTI measures served as a measure of perceived stress. They were state and trait anxiety, state and trait anger, and state and trait depression. Education was negatively correlated with state anxiety $(r=-0.274, p=0.001)$, state anger $(r=-0.217, p=0.009)$, state depression $(r=-0.231, p=0.006)$, and trait anxiety ( $\mathrm{r}=-0.2058, \mathrm{p}=0.014)$. Since years of education was related to stress and somewhat related to self-efficacy ( $\mathrm{r}=0.17, \mathrm{p}=0.042$ ) a partial correlation procedure (controlled for years of education) was performed for self-efficacy (GPSES) and the stress variables. Self-efficacy was negatively correlated with state anxiety $(\mathrm{r}=-0.312, \mathrm{p}=0.0001)$, state anger $(\mathrm{r}=-0.194, \mathrm{p}=0.021)$, state depression $(\mathrm{r}=-0.339$, $\mathrm{p}=0.0001)$, trait anxiety $(\mathrm{r}=-0.436, \mathrm{p}=0.0001)$, and trait depression $(\mathrm{r}=-0.3762, \mathrm{p}=0.0001)$. An analysis of variance was conducted to compare the means of the perceived stress variables for three job function groups (attendant basic or intermediate, attendant paramedic, and in-charge paramedic). Higher perceived stress was reported by both the attendant basic-intermediates and the in-charge paramedics $(\mathrm{p}<0.05)$ as compared to attendant paramedics who reported the lowest stress. The impact of education, self-efficacy, and job function may be related to the amount of skills available, the perception of confidence in those skills, and the amount of personal responsibility for patient care.
\end{abstract}

(C) 2006 Californian Journal of Health Promotion. All rights reserved.

Keywords: Perceived Stress, EMS, Paramedic, Education

\section{Introduction}

Selye (1976) argues that the human body responds predictably to a perceived stress stimulus and the effects of this stress can be causal for many disease processes. Exposure to stress is an inevitable part of daily life and some stress has the positive effect of increasing arousal and attention while preparing the body for action. On the other hand, exposure to stress can become harmful. The workplace is often an environment where repeated or long-term exposure to stressors occurs. Certain occupations such as emergency medical services (EMS) contain higher than average stress inducing activities. In fact, stress reactions such as burnout or illness are commonly seen in EMS professionals (Mitchell \& Bray, 1990). This results in an increased need for worksite health promotion programs that address perceived stress. The growing complexity of the job descriptions within EMS and the medical field in general contributes to a wide variety of stressors (Beaton \& Murphy, 1993). Emergency Medical Technicians (EMTs) and Paramedics are required to make independent decisions that may determine the fate of a critically ill or injured person. These decisions are often made in an environment that is less than perfect and possibly unsuitable. The negative consequences of this stress can include poor performance in critical situations (LeBlanc, MacDonald, Russel, McArthur, King, \& Lepine, 2005). This decrease in performance can include medical errors and impacts highly experienced professionals (LeBlanc, MacDonald, \& Lepine, 2004).

The occupational stress found in EMS can be categorized into the following groups: 1) 
administrative or organizational factors; 2) clinical or patient care factors; 3 ) factors related to the public; and 4) environmental factors not related directly to patient care (Boudreaux \& Mandry, 1995). These are issues that EMTs and Paramedics encounter on a daily basis. There is only a finite amount of adaptive energy that can be spent dealing with these stressors and the individual will, eventually, be negatively affected. At low levels some stressors can increase arousal and increase work quality. Also, EMS professionals may see certain situations as an "adrenaline rush" and not perceive them to be stressful. This is an important concept since the perception of stress is required for a response to be initiated. Not all stressors will create the same response in different individuals (Mason, 1971; Mason, 1975). In EMS, each call or run creates the possibility of a stress-inducing event. Boudreaux and Mandry's (1995) review indicated that the nature or perceived seriousness of the call relates to the amount of stress that an EMT or Paramedic encounters. One study even describes differences in stress between paid EMTs and volunteer EMTs (Allison, Whitley, Revicki, \& Landis, 1987). However, very little research has been completed to determine the impact of certification level, years of experience, or educational levels (outside of EMS) on occupational stress. It is possible that these and/or other factors contribute to the fact that some EMTs and Paramedics will see an event as low stress or even as eustress while others are taxed and distressed by the same situation.

The educational requirements to work as a certified paramedic vary greatly across America. Depending on where paramedic training is taken and the sponsoring agency, these programs can involve anything from a five-week condensed course to a two-year college based curriculum. While some bachelors and masters degree programs do exist for EMS providers, they are not normally an entry level education. The result is a population of EMS practitioners with a wide variety of educational preparation. One component of the study described here is to determine the impact of education on the perception of stress in the EMS context. Selfefficacy, which can be tied to education (Betz \&
Hackett, 2000), is a construct that involves an individual's self-belief in their ability to accomplish any given task. College education can influence an individual's self-beliefs in a positive direction (Betz \& Hackett, 2000). It has also been directly linked to the ability to cope with stress (Benight, Swift, Sanger, Smith \& Zeppelin, 1999).

With the increasing incidence in terrorist-type bombings and natural disasters occurring in the United States, more attention is being given to critical incident stress. A critical incident is defined as an occurrence that overwhelms an individual or a group's ability to cope with the stressors presented by the incident (Mitchell \& Bray, 1990). Typically we think of critical incidents that involve disasters, either man made or natural. However, the daily emergency calls to which Paramedics and EMTs respond are not always disasters, but they are still potential critical incidents by definition. Some examples are death or serious injury to a child, injury to a coworker, multiple casualty accidents, and excessive media exposure. These incidents are more common than earthquakes and federal building bombings. Research on critical incident stress has typically focused on the stress response to major disasters. For example Marmar, Weiss, Metzler, and Delucchi (1996) investigated emergency service workers that were involved in the Nimitz freeway collapse during the 1989 San Francisco earthquake. They found that personnel with characteristics such as shyness, inhibition, and external locus of control were more likely to exhibit negative dissociative responses and subsequent post-traumatic stress disorder. Limited research exists concerning the stress response Paramedics exhibit after critical incidents of lesser magnitude. In fact there is very little data on the impact of non-critical incident daily activities on stress in EMS professionals. We do know that the total number of runs an EMS crew makes (Mitchell, 1984) and the nature of each call (Boudreaux \& Mandry, 1996) can impact an individual's stress level. However, no research to date has been conducted on the combined effects of call volume, nature of call, time of day, and procedures performed. 
The primary intention of this study was to assess perceived stress in emergency medical service (EMS) professionals and relate these perceptions to certain demographic and work environment characteristics. Perceived psychological stress was studied across different job descriptions in EMS fieldwork. The relationship of education, self-efficacy, and satisfaction with social support on perceived stress were also investigated. This study is an effort to identify factors that mediate or exacerbate the perception of stress.

A second purpose of this study was an attempt to describe the relationship between the characteristics of a particular EMS professional's call history and the stress response it induced in that individual. This information allows the identification of potential stress inducing calls or situations before the physical or emotional signs and symptoms of a stress response develop. Emergency service organizations can use this information to reduce the negative consequences of a stressful work environment for their employees. EMS administration officials may find the information gained in this study to be extremely useful in establishing criteria to anticipate and possibly prevent stress in their personnel.

\section{Methods}

Several indicators of perceived stress were measured with Charles Speilberger's State Trait Personality Inventory (STPI). The measures of interest in this study were state and trait anxiety, state and trait anger, and state and trait depression. State and trait curiosity measures were also obtained. However, their usefulness as an indicator of stress in this population has not been determined and are not reported in the results described below. Satisfaction with social support was determined using the brief six item Social Support Questionnaire (Sarason, Levine, Basham \& Sarason, 1983). Self-efficacy was determined using the General Perceived SelfEfficacy Scale (Schwarzer, 1994). These established instruments and additional demographic questions were complied into a self-report mail questionnaire. The questionnaire was also made available on the World Wide Web through a password-protected form. This served as an additional option to returning the questionnaire by mail. Informed consent was obtained prior to survey completion. The study survey instruments and methods were approved by the Institutional Review Board (IRB) at Texas A\&M University.

Across the country emergency medical services are provided by various types of organizations. These include such as Fire Department-based EMS, Hospital-based EMS, Private EMS and Third Service EMS providers. Since there is a potential variability in perceived stress among the various types of EMS providers, only "third service" EMS organizations were used to identify potential study participants. The population further limited to urban settings since there are significant differences in call volume and staffing in rural EMS organizations. For this study, 203 questionnaires were mailed to randomly selected paramedics and EMTs from urban "third service" EMS providers in Texas. 166 questionnaires were returned by mail or submitted through the on-line option. Of these, 22 were inappropriate for inclusion in this study. The reasons for their elimination varied from incomplete data to unsolicited responses from personnel not meeting initial inclusion criteria. The remaining 144 usable questionnaires yielded a $71 \%$ response rate. Considering the traditionally low response rate among EMS study participants, this is an exceptionally good rate of return. Three weeks after the initial mail out, a post card reminder was sent to each nonrespondent in conjunction with emails sent from the directors of each EMS provider. The post card and email encouraged participation, provided the URL address for the online form, and offered and option to request and additional paper questionnaire. One additional mailing that included a new packet with an additional paper questionnaire was made two weeks after the post card reminders. As mentioned in Geick (1998, p. 56), Dillman (1983) states that a return rate of 53 to $67 \%$ can be considered average. Therefore, this study achieved a higher than average return rate.

\section{Results}

Selected demographic information can be found in Table 1 and Appendix A. Of the 144 study participants, 58 (40.3\%) were female and 86 
(59.7\%) were male. The mean age of the participants was $32 \pm 8.3$ years with a range from 18 to 60 years. This sample worked in the EMS field for an average of 8.1 years. The majority $(79.9 \%)$ of the participants were Certified Paramedics (EMT-P, $\mathrm{n}=70$ ) or Licensed Paramedics (LP, $n=45$ ). It is important to note that Texas EMS certification levels include two levels of paramedic (certified and licensed). At the time of this study, the difference in the two levels was in the amount of college education the provider had obtained. The scope of practice and level of technical skill for the two levels were essentially the same. This unique situation does not exist in many areas of the country and allows the amount of college education to be examined independently while holding technical skill or capability relatively constant. The remaining participants were equally distributed among the other certification levels. Since one of the main intentions of this study was to evaluate the affects of patient care on perceived psychological stress in EMS professionals, the abundance of paramedic level providers in the sample is helpful. These providers are more directly responsible for patient care activities and would be more impacted by this stressful aspect of the EMS profession.

The larger number of paramedic level participants impacted the frequencies of the job responsibilities represented in this study. The term attendant implies a role of assistant. Although these personnel do participate completely in patient care, they do not have ultimate responsibility for the care of the patient which is an important contributor to perceived stress. Sixteen percent of the respondents were currently working in the capacity of attendant EMT-Basic or attendant EMT-Intermediate. Another $18.8 \%$ were attendant paramedics. The majority of the respondents were in more responsible positions such as In-Charge Paramedic (46.5\%) and Field Supervisor (9\%). Another 9.7\% $(n=14)$ respondents indicated a primary job responsibility other than those listed above. Examples are administration, medical oversight, education, and maintenance.

Table 1

Demographic characteristics

\begin{tabular}{|l|c|c|c|c|c|}
\hline \multicolumn{1}{|c|}{ Variable } & Mean & Std. Dev. & Minimum & Maximum & N \\
\hline Age (years) & 32 & 8.31 & 18 & 60 & 144 \\
\hline Experience in EMS(years) & 8.1 & 5.48 & 0 & 28 & 144 \\
\hline Years at current certification & 4.4 & 4.1 & 0 & 18 & 144 \\
\hline Education (years past HS) & 2.9 & 1.65 & 0 & 12 & 144 \\
\hline
\end{tabular}

Health status was not directly assessed in this investigation. However, two items on the questionnaire did probe the perceptions of the participant's current health status in the last six months and the perceptions of the change in health status compared to before beginning work in EMS. A large proportion of the respondents perceived good health $(n=72,50 \%)$ or very good health ( $\mathrm{n}=21,14.6 \%)$ in the last six months (see Table 2 and Figures 1 and 2). Very few (n=9, $6.3 \%$ ) had current perceptions of health that were bad or very bad. An interesting result was the slight difference in the perceptions of how EMS work has impacted health. Although the general perception of current health was good, more respondents indicated a negative impact of EMS on their health. Thirty six percent reported that their health was worse or much worse since they began work in EMS. Since the current health question only refers to the last six months and many of the respondents have been working in EMS for many years, this does not necessarily indicate contradictory responses. 
Table 2

Perceptions of health

\begin{tabular}{|l|c|c|}
\hline \multicolumn{1}{|c|}{ Variable Name } & Frequency & Percent \\
\hline Perception of current health (last six months) & & \\
\hline Very bad & 1 & 0.7 \\
\hline Bad & 8 & 5.6 \\
\hline Neither good or bad & 40 & 27.8 \\
\hline Good & 72 & 50.0 \\
\hline Very good & 21 & 14.6 \\
\hline Missing data & 2 & 1.4 \\
\hline Total & 144 & 100 \\
\hline Comparison of health compared to before beginning work in EMS & & \\
\hline Much worse & 6 & 4.2 \\
\hline Worse & 46 & 31.9 \\
\hline Same & 73 & 50.7 \\
\hline Better & 17 & 11.8 \\
\hline Much better & 2 & 1.4 \\
\hline Total & 144 & 100 \\
\hline
\end{tabular}

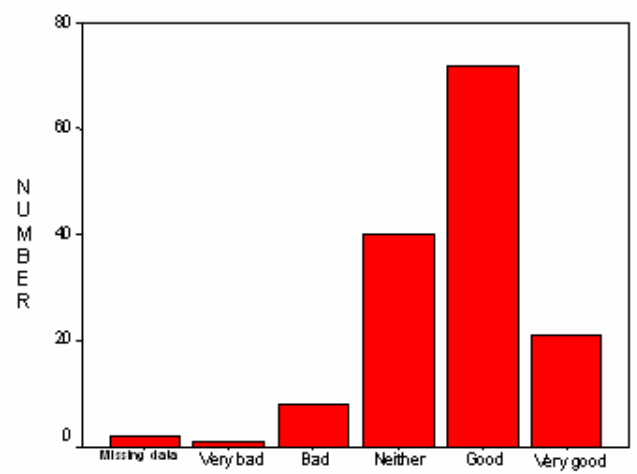

Figure 1

Perception of current health (last six months)

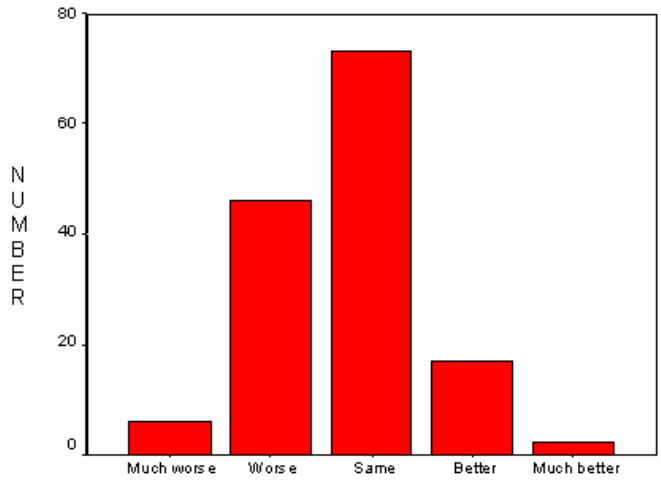

Figure 2 Impact of EMS work on health
A partial correlation procedure was used to determine the relationship between stress and years of college experience (see Table 3). Since social support has previously been shown to be related to most measures of stress, its relationship was accounted for in the procedure by controlling for satisfaction with social support. However, since social support satisfaction was not related to years of college education, there was no significant difference in the partial correlation or the zero order correlation coefficient. The differences seen in Table 3 can be attributed to missing data. Four subjects did not complete the social support questions completely.

Measured as a continuous variable (years), education was negatively correlated with state anxiety $(\mathrm{r}=-0.274, \mathrm{p}=0.001)$, state anger $(\mathrm{r}=-$ $0.217, \mathrm{p}=0.009)$, state depression $(\mathrm{r}=-0.231$, $\mathrm{p}=0.006)$, and trait anxiety $(\mathrm{r}=-0.2058, \mathrm{p}=0.014)$. Visual inspection of the data plotted on an $\mathrm{X}-\mathrm{Y}$ 
axis indicates the presence of a possible linear relationship and there were no extreme data points noted. Of the six perceived stress variables in this study, only $7.5 \%$ of state anxiety, $4.7 \%$ of state anger, $5.3 \%$ of state depression, and $4.2 \%$ of trait anxiety can be explained as shared variance with years of college education. While these results are statistically significant, only a small portion of the variance in perceived stress can be explained by years of college education as indicated by $\mathrm{r}^{2}$.

Table 3

Relationship of stress and years of education

\begin{tabular}{|l|c|c|r|c|c|r|}
\hline \multicolumn{1}{|c|}{ Variable $_{\mathbf{1}}$} & \multicolumn{1}{c|}{$\mathbf{R}_{\mathbf{1 2}}$} & $\mathbf{R}_{\mathbf{1 2}}{ }^{2}$ & $\mathbf{p}$ value & $\mathbf{R}_{\mathbf{1 2 . 3}}$ & $\mathbf{R}_{\mathbf{1 2 . 3}}{ }^{2}$ & p value \\
\hline State Anxiety & -0.229 & 0.052 & 0.006 & -0.274 & 0.075 & 0.001 \\
\hline State Anger & -0.194 & 0.038 & 0.020 & -0.217 & 0.047 & 0.009 \\
\hline State Depression & -0.151 & 0.023 & 0.071 & -0.231 & 0.053 & 0.006 \\
\hline State Curiosity & +0.040 & 0.002 & 0.632 & -0.074 & 0.005 & 0.380 \\
\hline Trait Anxiety & -0.145 & 0.021 & 0.084 & -0.206 & 0.042 & 0.014 \\
\hline Trait Anger & -0.122 & 0.015 & 0.144 & -0.145 & 0.021 & 0.083 \\
\hline Trait Depression & -0.064 & 0.004 & 0.445 & -0.132 & 0.017 & 0.116 \\
\hline Trait Curiosity & +0.086 & 0.007 & 0.305 & -0.132 & 0.017 & 0.117 \\
\hline
\end{tabular}

$\mathrm{R}_{12.3}$ : 1 = stress variable listed in first column; $2=$ years of college education; $3=$ social support (control variable). Note: zero order correlation $(n=144)$ but first order correlation coefficient $(n=140)$

An additional research question investigated the relationship between self-efficacy and stress in EMS professionals. Although self-efficacy was not significantly correlated with years of EMS experience or job responsibility, there was a slight positive correlation with years of college education ( $\mathrm{r}=0.17, \mathrm{p}=0.042)$. As mentioned above, years of education was somewhat related to stress. Therefore a partial correlation procedure was performed that controlled for years of college education (see Table 4). After this control, self-efficacy was positively correlated with state curiosity $(r=0.373$, $\mathrm{p}=0.0001)$ and trait curiosity $(\mathrm{r}=0.419$, $\mathrm{p}=0.0001$ ). It was negatively correlated with state anxiety $(\mathrm{r}=-0.312, \mathrm{p}=0.0001)$, state anger $(r=-0.194, p=0.021)$, state depression $(r=-0.339$, $\mathrm{p}=0.0001)$, trait anxiety $(\mathrm{r}=-0.436, \mathrm{p}=0.0001)$, and trait depression ( $\mathrm{r}=-0.3762, \mathrm{p}=0.0001)$. In other words, self-efficacy was significantly related to all measures of perceived stress except trait anger. A non-significant relationship of $\mathrm{r}=-$ $0.146(p=0.083)$ was found between trait anger and self-efficacy. The zero order correlation coefficient was also non-significant $(\mathrm{r}=-0.163$, $\mathrm{p}=0.051)$.

The third research focus in this study was to determine if a difference exists in perceived psychological stress among the job responsibilities of the EMS professional. The job function of field supervisor was not consistently defined by each of the participating EMS services. Some field supervisors worked on an ambulance as part of a standard crew and some worked independently by responding to calls in a separate chase car. There were also differences in the amount of patient care responsibilities of each supervisor. Because of these findings, only Attendant Basic/Intermediates, Attendant Paramedics, and In-charge Paramedics were included in the ANOVA for job function.

The summary table for the analysis of variance procedure on job responsibility can be found in Table 5. A significant F statistic was found state anxiety, state depression, trait anxiety and trait depression. Therefore, the null hypotheses that no difference exists among the job function 
groups were rejected for these variables. A posthoc analysis was conducted using Fisher's least significant difference procedure. According to Howell (1997), this procedure is appropriate for determining differences between three means. It is also one of the most powerful of the common post-hoc multiple comparison procedures. Considering the exploratory nature of this study, this is helpful.

Table 4

Relationship of stress and self-efficacy

\begin{tabular}{|l|l|l|l|l|l|l|}
\hline \multicolumn{1}{|c|}{ Variable $_{\mathbf{1}}$} & \multicolumn{1}{|c|}{$\mathbf{R}_{\mathbf{1 2}}$} & $\mathbf{R}_{\mathbf{1 2}}{ }^{2}$ & \multicolumn{1}{|c|}{$\mathbf{p ~ v a l u e}$} & \multicolumn{1}{|c|}{$\mathbf{R}_{\mathbf{1 2 . 3}}$} & $\mathbf{R}_{\mathbf{1 2 . 3}}{ }^{2}$ & \multicolumn{1}{|c|}{$\mathbf{p ~ v a l u e ~}$} \\
\hline State Anxiety & -0.338 & 0.114 & 0.0001 & -0.312 & 0.097 & 0.0001 \\
\hline State Anger & -0.220 & 0.048 & 0.008 & -0.194 & 0.038 & 0.021 \\
\hline State Depression & -0.356 & 0.127 & 0.0001 & -0.339 & 0.115 & 0.0001 \\
\hline State Curiosity & +0.374 & 0.140 & 0.0001 & +0.373 & 0.139 & 0.0001 \\
\hline Trait Anxiety & -0.450 & 0.203 & 0.0001 & -0.436 & 0.190 & 0.0001 \\
\hline Trait Anger & -0.163 & 0.027 & 0.051 & -0.146 & 0.021 & 0.083 \\
\hline Trait Depression & -0.381 & 0.145 & 0.0001 & -0.376 & 0.141 & 0.0001 \\
\hline Trait Curiosity & +0.426 & 0.181 & 0.0001 & +0.419 & 0.176 & 0.0001 \\
\hline
\end{tabular}

$\mathrm{R}_{12.3}$ : 1 = stress variable listed in first column; $2=$ general perceived self-efficacy; $3=$ years of college education (control variable) $(\mathrm{n}=144)$

Table 5

ANOVA summary table for job function

\begin{tabular}{|l|l|r|r|r|r|r|}
\hline & & Sum of Squares & df & Mean Square & \multicolumn{1}{c|}{ F } & Sig. \\
\hline SANX & Between Groups & 216.170 & 2 & 108.085 & 3.455 &. $\mathbf{0 3 5}$ \\
\hline & Within Groups & 3566.599 & 114 & 31.286 & & \\
\hline & Total & 3782.769 & 116 & & & \\
\hline SANG & Between Groups & 116.858 & 2 & 58.429 & 2.145 & .122 \\
\hline & Within Groups & 3105.262 & 114 & 27.239 & & \\
\hline & Total & 3222.120 & 116 & & & \\
\hline SDEP & Between Groups & 228.719 & 2 & 114.359 & 3.531 &. $\mathbf{0 3 3}$ \\
\hline & Within Groups & 3691.862 & 114 & 32.385 & & \\
\hline & Total & 3920.581 & 116 & & & \\
\hline TANX & Between Groups & 193.721 & 2 & 96.861 & 3.223 & $\mathbf{. 0 4 3}$ \\
\hline & Within Groups & 3425.971 & 114 & 30.052 & & \\
\hline & Total & 3619.692 & 116 & & & \\
\hline TANG & Between Groups & 90.156 & 2 & 45.078 & 1.130 & .326 \\
\hline & Within Groups & 4545.844 & 114 & 39.876 & & \\
\hline & Total & 4636.000 & 116 & & & \\
\hline TDEP & Between Groups & 239.007 & 2 & 119.503 & 3.126 & $\mathbf{. 0 4 8}$ \\
\hline & Within Groups & 4358.070 & 114 & 38.229 & & \\
\hline & Total & 4597.077 & 116 & & & \\
\hline
\end{tabular}

SANX- State anxiety; SANG- State Anger; SDEP- State depression; TANX- Trait anxiety; TANG-

Trait Anger; TDEP- Trait depression 
Appendix B and Figures 3 through 6 present the results of the multiple comparison tests. Attendant Paramedics have significantly lower state anxiety than Attendant Basic-Intermediates or In-Charge Paramedics. Since there was not a significant F-statistic for state anger or trait anger, it is assumed no significant differences exist between the job function groups on these

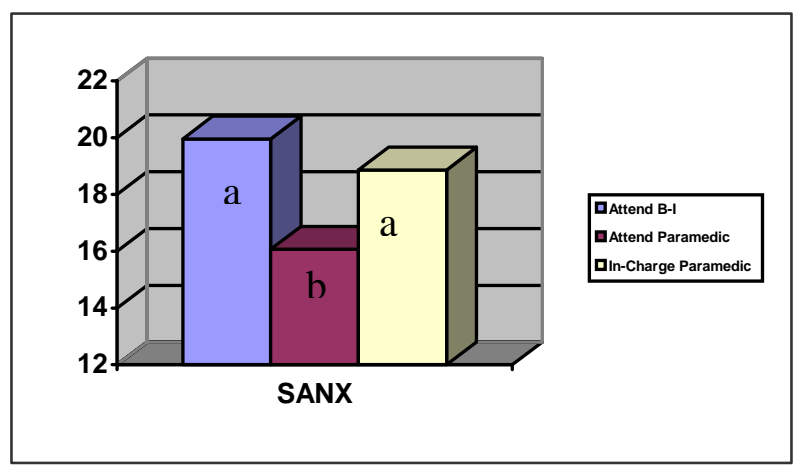

Figure 3

State anxiety and job function. Means with the same letter are not significantly different (p.>0.05)

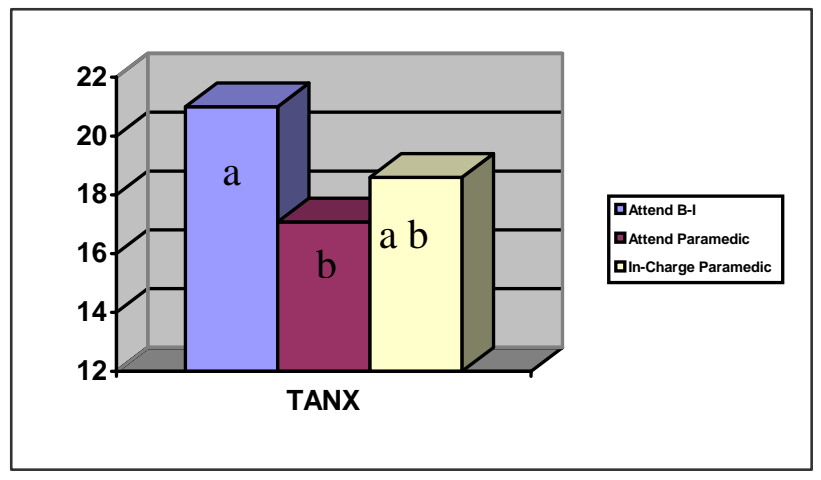

Figure 5

Trait anxiety and job function. Means with the same letter are not significantly different (p.>0.05)

The primary categorical difference between these groups is level of responsibility. In-Charge Paramedics are ultimately responsible for all aspects of patient care. In the services participating in this study, every ambulance has two crew members, one of which serves as an in-charge paramedic. This in-charge paramedic position usually requires additional experience, variables. For the state depression variable, Attendant Basic Intermediates were only different from Attendant Paramedics. The same is true for the trait anxiety characteristic. However, on trait depression, Attendant Paramedics were lower than both In-charge Paramedics and Attendant Basic-Intermediates.

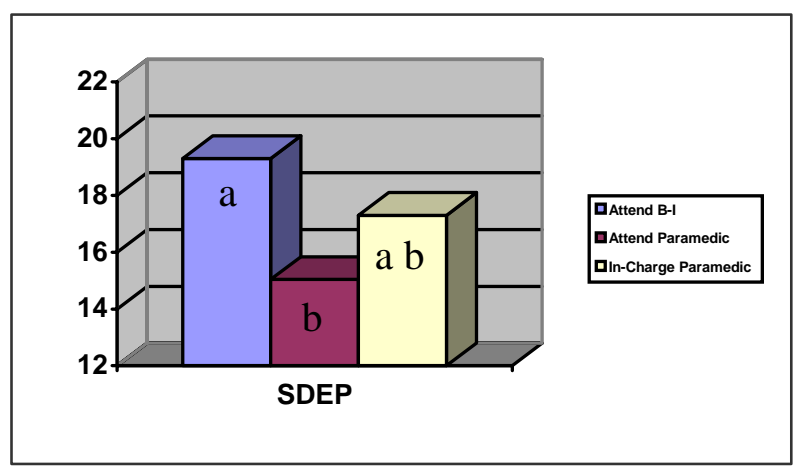

Figure 4

State depression and job function. Means with the same letter are not significantly different (p.>0.05)

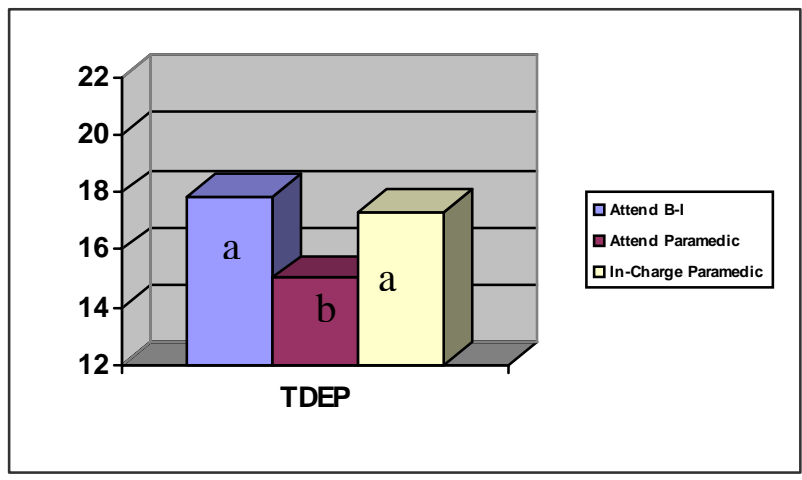

Figure 6

Trait depression and job function. Means with the same letter are not significantly different (p.>0.05)

training, and testing beyond the paramedic certification course. The other crew member is, in most cases, an Attendant Basic-Intermediate or Attendant Paramedic. The role of these two positions is similar. They serve as an assistant to the In-Charge Paramedic. Considering the different levels of training, they "assist" at different levels of skill and responsibility. The 
results of this study imply that both skill level and ultimate responsibility play a role in the perception of stress. Those with less training had higher stress and those with more responsibility had higher stress. Interestingly, the attendant paramedic perceived the least amount of stress. These personnel have most of the requisite skills to care for a patient, but do not have ultimately accountability for quality of care.

As a part of inquiring about education, the questionnaire also included a question on current attendance to school above and beyond current work responsibilities. Participation in school on a part time basis was negatively correlated with years of EMS experience $(\mathrm{r}=-0.281, \mathrm{p}=0.001)$, length of certification $(\mathrm{r}=-0.249, \mathrm{p}=0.003)$, and age $(\mathrm{r}=-0.373, \mathrm{p}=0.0001)$. However, part-time school attendance was not correlated with years of education, or sex. Apparently, younger EMS professionals with less experience are seeking education beyond standard EMS training.

A critical incident can be defined as any single event that stresses or overwhelms the available coping resources of the individual or individuals involved. For this study, participants were excluded if they had recently (last two years) worked a disaster or large scale event. These events can complicate the interpretation of perceived stress due to the nature of such exposures. Disasters, however, are not the only events with the capacity to be a critical incident. Pediatric deaths, having an accident in the ambulance, and working an accident where the victim is known personally by the rescuer can all be critical incidents. These are events are actually rare and are not part of an EMS professional's normal activity. Therefore they are critical incidents. Another type of stressful event that may occur, but is not considered a critical incident is a duty stressor. These are events that are specific to the job of EMS that may be a critical incident to a typical layperson, but occur on a regular basis in EMS and are not considered critical incidents to this population. Extremely gruesome injuries, exposure to death and dying, and responding to vulnerable victims (i.e., abused children) are all examples of duty stressors. The questionnaire utilized in this study included two questions that probed the number of times each of the above events (critical incidents and duty stressors) happened in the last six months.

As suggested in the previous literature (Mitchell \& Bray, 1990), the number duty stressor exposures were not correlated with any of the perceived stress variables. This confirms the notion that EMS professionals can become somewhat stress resistant to certain common work related events. The number of critical incidents was, however, correlated with state anger $(\mathrm{r}=0.171, \mathrm{p}=0.041)$, trait anger $(\mathrm{r}=0.242$, $\mathrm{p}=0.004)$, and trait depression $(\mathrm{r}=0.166$, $\mathrm{p}=0.047)$. Since these events are not everyday occurrences, apparently the EMTs and paramedics are not immune to their stressful impact.

One final ancillary finding involves the perception of call volume reported by participants in this study. They were asked a question on how they felt about the number of calls they respond to on a regular basis. The six choices ranged from "too slow" to "outrageous". It was anticipated that those EMS professionals on either end of the call volume spectrum would be more stressed that those reporting perfect amounts of calls. It is well known that too much or too little workload can be distressing. On the other hand, a certain amount of workload is required to maintain attention, efficiency, and overall performance.

An analysis of variance was conducted by placing participants into groups based on their perception of call volume. The summary report for the ANOVA can be found in Appendix C. A significant $F$ statistic was found for all six dependent stress variables. A Fischer's LSD multiple comparisons post-hoc analysis was conducted to determine where the differences occurred. The means have been plotted in Figures 7 though 12. It can be seen in these figures that the predicted relationship between perceived call volume and stress held true from "too slow" up to "too much." However, those reporting "outrageous" call volumes reported less stress than expected. This is a surprising finding and may have significant implications. 


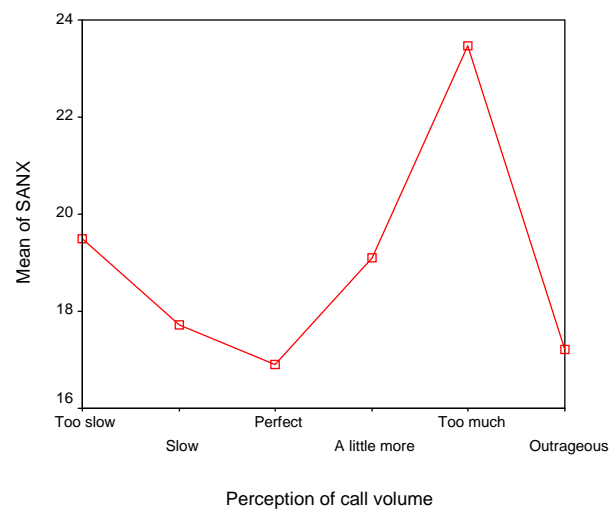

Figure 7

State anxiety and perception of call volume

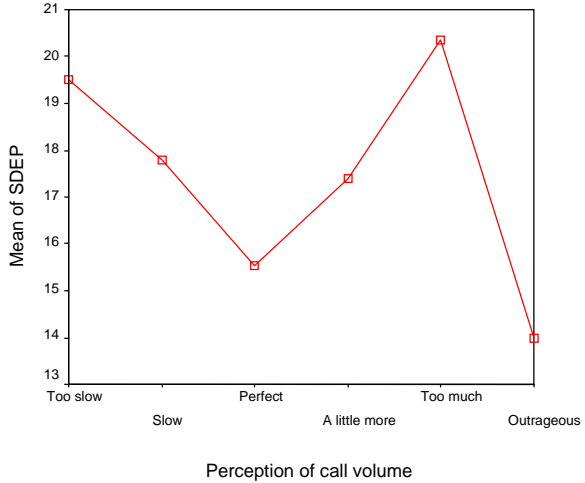

Figure 9

State depression and perception of call volume

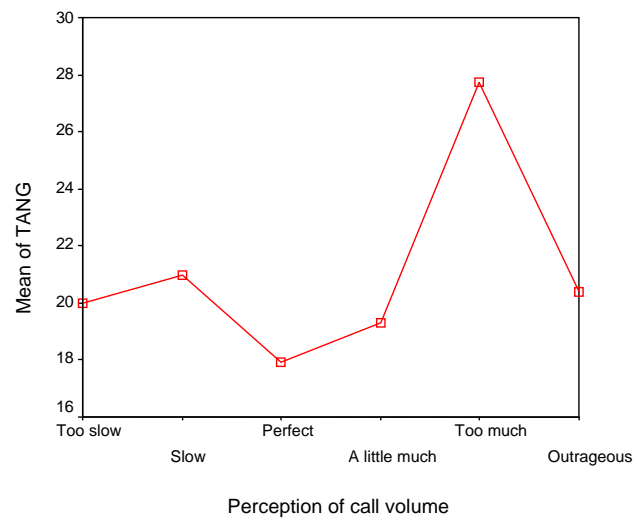

Figure 11

Trait anger and perception of call volume

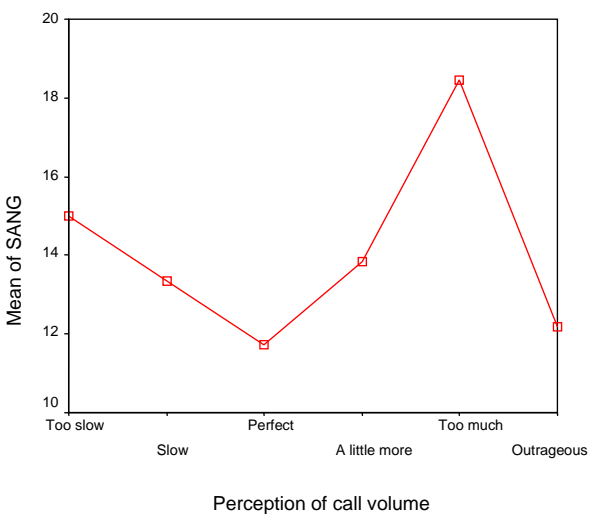

Figure 8 State anger and perception of call volume

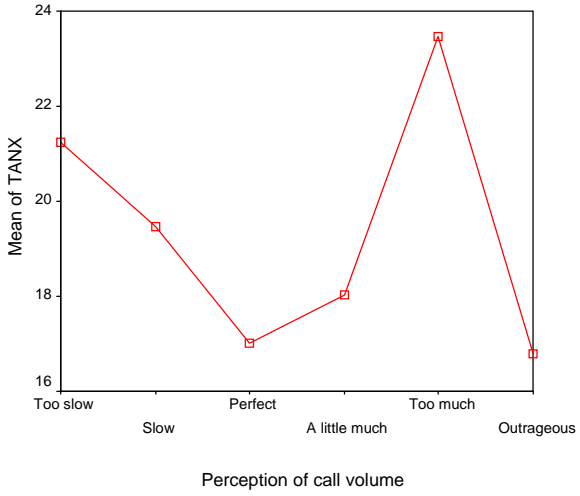

Figure 10

Trait anxiety and perception of call volume

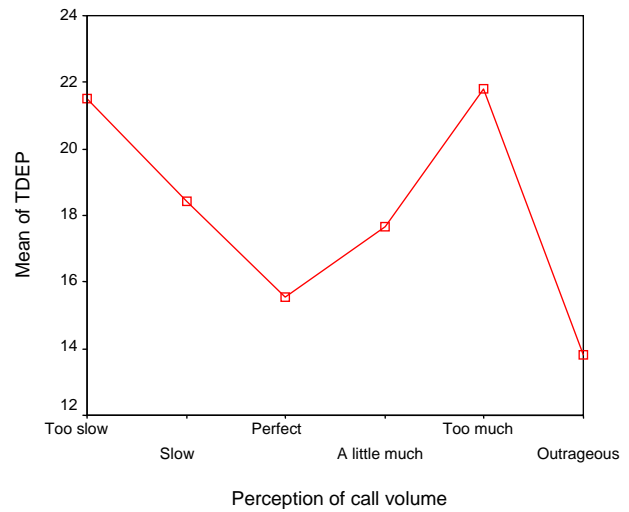

Figure 12

Trait depression and perception of call volume 


\section{Discussion and Conclusions}

Education, job responsibility, and self-efficacy are all factors that mitigate or exacerbate the effects of EMS stress. This investigation has demonstrated a weak relationship between years of college education and perceived stress. The research design and statistics utilized here do not allow inference into causal relationships. However, some discussion can be made on the relationship of education, job function, and stress. There are two potential mechanisms behind the mitigation of stress with increased education. First, it is possible that those participants with more years of college education have developed more coping skills and strategies to deal with stress. Since this study did not attempt to describe or quantify coping skills, confirmation of this possibility is not possible. Another potential explanation is the fact that education was positively correlated with increased job responsibility $(r=0.210$, $\mathrm{p}=0.017$ ). At first, this may seem illogical since job responsibility is associated with an increase stress. However, at lower levels an increase in education is directly associated with paramedic training and the job responsibility of attendant paramedic reported the lowest perceived stress. Therefore, an EMT-Basic or Intermediate that goes on to school to complete the paramedic certification will move to the attendant paramedic position that produces lower perceived stress as reported here. While this explanation is true for the population studied, many EMS organizations move newly trained paramedics directly into In-Charge status. This practice would likely yield different results than described here.

The job functions studied here are only those in direct patient care roles. Administrators and those reporting an "other" job function were excluded from this analysis. Field supervisors were also excluded for reasons stated earlier. These limitations were designed to limit the variation in potential sources of stress while including patient care as a source. For the most part, attendant basics and intermediates were similar in perceived stress to in-charge paramedics. However, attendant paramedics appear more stress resistant. There are two primary differences among these groups. They are training level and responsibility. Attendant basics and intermediates have not received the additional advanced training that paramedics receive. This places them at a disadvantage to help certain patients in certain situations. Even though personnel at this level are not ultimately responsible for patient care, they may feel less equipped to help in certain circumstances. At the other end of the job responsibility spectrum are in-charge paramedics. Personnel working in this capacity are ultimately responsible for all patient care actions, including those performed by their attendant partners. This is likely the stressinducing factor for this job function. Attendant paramedics do have the requisite advanced skills to perform in most situations and do not perceive stress from lack of capabilities. Also, because they have not yet attained the level of "in-charge" status, they are not ultimately responsible for the patient and do not report stress from this aspect of patient care. It is likely that there is an interaction between skills and capabilities and responsibility. It is recommended that follow up investigations specifically address this interaction. It is possible that this is not an EMS specific phenomenon. The rise in popularity of physician assistants may provide a similar investigative opportunity in another profession. Physician assistants provided similar care to patients as physicians. However, they have less ultimate responsibility due to the requirement of physician oversight.

For this investigation and the instruments used, general perceived self-efficacy pertains to the optimistic beliefs about an individual's ability to cope with a large variety of stressors. Selfefficacy was significantly related to all of the perceived stress variables. This suggests that an individual's self-belief in their capabilities is related to the perception of stress. This finding corroborates the assumptions made earlier about the relationship of skill capabilities and responsibilities. Individuals with more responsibility will more than likely place higher standards upon themselves for patient care. If an individual's self-evaluation does not meet or exceed the expected standards, perceived stress will increase. Apparently, self-efficacy plays a significant role in the perception of stress in an EMS population. 
The theoretical implications of these findings are plentiful. Karasek's (1979) job-demand: job decision-latitude model of workplace stress is supported by these findings. In brief summary, the model defines job demands as those pressures and required actions in the workplace. An example might be to work fast and efficient to save lives in unusual and unpredictable situations. Job decision latitude has two components, decision authority and skill discretion (Ganster, 1991). In EMS, authority is given to in-charge paramedics directly from the medical director and skills are obtained through additional training. It seems that those EMS professionals with low decision latitude and skill discretion, such as attendant basics and intermediates perceive more stress. Karasek's complete model is valid in a sub-section of this population. However, Attendant paramedics and in-charge paramedics perceive stress differently than the model would predict. Attendant paramedics do have less stress and this may be attributable to increased skill discretion. They do not have improved authority. On the other hand, in-charge paramedics do have a significant amount of authority and skill discretion, but their perceived stress is increased. Therefore these data support only the skill discretion component of the model. Apparently the responsibility and related accountability that comes with authority limits the application of Karasek's model within the EMS population. This is possibly due to the difference in the consequences (i.e., death of a patient) of a bad decision in the EMS setting as compared to a more traditional work environment where Karasek's model has been shown to be consistently valid. Overall, skill discretion decreases perceived stress and authority with increased responsibility exacerbates perceived stress. This phenomenon may be true in other populations as well. Future studies might compare liberal and conservative EMS protocols as a measure of decision latitude. Protocols are those standing orders that allow an in-charge paramedic the ability to function independently.

The sample drawn for this study had a significantly higher score for self-efficacy that the normative data provided with the GPES instrument. This may or may not be true of the entire EMS population. This investigation limited participation to full time EMS professionals at larger third service MICU qualified services in urban settings. Services of this type attract and retain some of the best paramedics and EMTs in the industry. Personnel at these services are more likely to be paramedics because of a love for the job and a love for patient care. Fire department-based paramedics are sometimes in the paramedic role as an entry-level requirement to work at the fire department and may not be as personally vested in the medical aspects of their job since it is one of many job responsibilities (i.e., fire fighting). Therefore, it is possible that the range of reported self-efficacy in this sample is truncated and provides a higher mean score than a more loosely defined EMS population. Further investigations can be done to determine the differences between provider types (third service, fire department based EMS, private providers...) on several variables including stress and self-efficacy.

A commonly reported stressor in the EMS field is administrative or organizational difficulty. In fact, many sources have described this as the number one reported stressor in EMS (Boudreaux \& Mandry, 1995, Young \& Cooper, 1997). The present investigation did not account for or control administrative stressors. This potential source of stress may account for some of the findings. For example, in-charge paramedics are more involved with administration and may be more affected by these stressors. This is an alternative explanation of this particular job functions reported stress as compared to increased patient care responsibility.

Another characteristic about the sample of EMS professionals recruited for this study that may differ from the entire population is years of experience. The participants in this study have been practicing in EMS for $8.1 \pm 5.48$ years. This is longer than the national average. The reasons suggested above concerning the higher than normal self-efficacy may also contribute to longevity. These unknown and unmeasured characteristics may allow these participants to stay in the field longer than expected and may 
also provide a level of stress resilience. Therefore, these findings may indicate a smaller stress response than would be expected in a more representative sample.

As mentioned above, one objective of this study was to describe the perceived stress response from patient care factors. Hobofoll (1998) states many stressors may have both positive and negative effects. For example, a raise in salary from a promotion may be positive, but the other issues such as moving or increased responsibility may be distressing. The care of a seriously ill or injured person may have the same confounding impact. Some aspects of the call may be distressing. However, many EMTs and paramedics look forward to the really serious calls. Many see this as a chance to use skills and challenge their capabilities. It is the appraisal of the stressor by the individual that determines the response in these cases. Obviously, the general population will appraise major disasters and other serious critical incidents as stressful. The physiological response will be similar as well. However, every day normal stressors may have differential impacts based on appraisal. This has already been demonstrated by comparing this sample's lack of perceived stress to increased duty stressors. Most of the non-EMS public would find any one of those events very distressing. The EMS personnel have learned to appraise these as less serious through experience, exposure and possibly desensitization.

Another often-studied stress issue in EMS is the impact of critical incidents. These events are atypical calls or situations that have the capacity to overwhelm the normal capacity to cope of those involved. These events can lead to debilitating psychological problems such as post-traumatic stress disorder. The impact of less significant calls and events that occur on a daily basis may effect an individual's ability to cope with a critical incident when it occurs. This study has confirmed the relationship of stress and the length of time working in EMS. Others have described a decrease in performance and ability to function independently over time as a result of chronic stress (Mitchell \& Everly, 1995). These authors also imply an increased susceptibility to critical incidents as these functional impairments occur.

The impact of a critical incident is a function of the subjective interpretation of that incident. In fact, it is this interpretation of normal physical, emotional and psychological responses to critical incidents that determine whether an incident will produce pathological stress disorders (Everly \& Mitchell, 2000). The impact of long term cumulative stress on this subjective interpretation is difficult to predict. If an EMS worker's cognitive function is impaired with workplace stress, as suggested in Galloucis (1995), there may be an increased interpretation of seriousness with a given event. Therefore, the pile-up effect of cumulative stress may raise the subjective impact of a given situation from normal to above a critical incident threshold. This theoretical critical incident threshold will also vary from individual to individual. The present study provides evidence that college education and self-efficacy may raise this threshold and decrease the impact of small magnitude events in EMS.

\section{Recommendations}

One obvious recommendation to prevent the effects of EMS stress is to develop worksite health promotion programs in the EMS setting that will make stress management services easily available to EMS professionals. The data presented here can guide the implementation of such services. For example, it appears that newly hired EMT-basics and those paramedics recently promoted to "in-charge" status should receive the most attention for a stress management intervention. Within the larger group of EMS professionals, these personnel can be considered a priority population for planning. In addition, the planned programs should be designed to improved perceived self-efficacy.

Services such as critical incident stress management (CISM) teams have shown significant benefits in mitigating the impact of critical incidents within several different public service populations (Everly \& Mitchell, 1999). Therefore, worksite health promotion programs could also include capabilities to respond to various levels of critical incidents. The 
combination of appropriately planned stress prevention/management programs and the ability to respond to and possibly mitigate stress producing events could result in improved wellbeing within the EMS workplace.

Any recommendation related to the availability of services for EMS personnel needs to consider the culture found in the EMS workplace. It is common for EMS personnel to deny the impact of their work on psychological wellbeing. Many paramedics believe they should be immune to the effects of call related stress. This bravado prevents many EMS professionals from feeling comfortable asking for help. More research is needed to identify factors that promote a positive culture that is receptive to proven coping strategies. Some research has been conducted that suggests and open line of communication between line personnel and supervision as a potential method of reducing stress (Allison, Whitley, Revicki. \& Landis, 1987). Future experimental designs that incorporate this conceptual model might demonstrate the impact of more open atmosphere on perceived stress.

These findings may provide rationale for structured staffing policies on EMS units. Attendant paramedics perceive less stress than in-charge paramedics. However, both bring a significant amount of advanced skill into patient care situations. The paring of these two personnel may be the most beneficial approach to staffing an ambulance. More research is necessary to determine if two in charge paramedics on the same unit would yield the same stress levels as a single in charge paramedic partnered with an EMT-Basic. It may be possible that perceived stress will decrease when a partner is of equal skill and responsibility.

The following list summarizes the recommendations made within the discussion above. Additional recommendations for future studies on EMS stress are also provided.

1. Prioritize new EMT-Basics and those Paramedics recently moved to "in-charge" status for stress management programs.

2. Design programs to improve self-efficacy

3. Utilize protocols as a measure of decision latitude to validate Karasek's job-decision: Job latitude model of workplace stress.

4. Evaluate the interaction of skill availability and ultimate responsibility by way of a two factor analysis of variance.

5. Evaluate the relationship of personality characteristics and perceived stress in the EMS population.

6. Investigate the impact of self-efficacy improvement programs on perceived stress. This may be done in the field or classroom.

7. Measure physiological indicators of stress. For example, catecholamines or cortisol in the saliva could be measured during and after certain EMS stress exposures.

8. Suggestions for potential dependant variables in EMS stress investigations can be found in Table 6 .

Table 6

Potential dependent variables*

\begin{tabular}{|c|c|c|}
\hline Affective-Cognitive & Behavioral & Physiological \\
\hline & & \\
\hline Subjective measures: & Social withdrawal/isolation & Immunocompetence \\
\hline Anxiety & Job Performance & Cardiovascular reactivity \\
\hline Depression & Lost work days & Neuroendocrine markers \\
\hline Anger & Medical claims & \\
\hline Dissociative symptoms & & \\
\hline Hostility & & \\
\hline
\end{tabular}

*Modified from Everly and Mitchell (1999) page 207 


\section{References}

Allison, E. J., Whitley, T. W., Revicki, D. A. \& Landis, S. S (1987). Specific occupational satisfaction and stresses that differentiate paid and volunteer EMTs. Annals of Emergency Medicine, 16, 676679.

Beaton, R. D., \& Murphy, S. A. (1993). Sources of occupational stress among firefighter/EMTs and firefighter/paramedics and correlations with job-related outcomes. Prehospital and Disaster Medicine, 8(2), 140-150.

Benight, C. C., Swift, E., Sanger, J., Smith, A. \& Zeppelin, D. (1999). Coping self efficacy as a mediator of distress following a natural disaster. Journal of Applied Social Psychology, 29, 2443-2464.

Betz, E. B., \& Hackett, G. (2000). Manual for the occupational self-efficacy scale. Retrieved August 1, 2000, from http://seamonkey.ed.asu.edu/ gail/occse1.htm\#intro

Boudreaux, E., \& Mandry, C (1995). Sources of stress among emergency medical technicians (Part-I): What does the research say? Prehospital and Disaster Medicine, 11(4), 296-301.

Boudreaux, E., Mandry, C., \& Brantley, P. J. (1996). Patient care and daily stress among emergency medical technicians. Prehospital and Disaster Medicine, 11(3), 193-194.

Elias, M (2005). Katrina weighs heavily on first responders. USA Today.

Everly, G. S., \& Mitchell, J. T. (1999). Critical incident stress management (2nd ed.). Ellicott City, MD Cheveron Publishing.

Everly, G. S. \& Mitchell, J. T. (2000). Critical incident stress management: Advanced group crisis interventions workbook. Ellicott City, MD: International Critical Incident Stress Foundation.

Galloucis, M. (1995). The psychological impact of repeated indirect exposure to trauma: An investigation of the role of perceived social support and hardiness as moderators of disruption in cognitive schemata among a sample of paramedics. Doctoral Dissertation, Loyola University, Chicago, Illinois.

Ganster, D. C., \& Schaubroeck, J. (1991). Work stress and employee health. Journal of Management, 17(2), 235-271.

Ganster, D. C., Fusilier, M. R. \& Mayes, B. T. (1986). Role of social support in the experience of stress at work. Journal of Applied Psychology, 71, 102-110.

Gieck, E. G. (1998). Occupational stress of female police officers. Doctoral Dissertation, Texas A\&M University, College Station, Texas.

Hobfoll, S. E., Schwarzer, R., \& Chon, K. K. (1998). Disentangling the stress labrinth: Interpreting the meaning of the term stress as it is studied in health context. Anxiety Stress and Coping, 11(3), 181-212.

Howell, D. C. (1997). Statistical methods for psychology (4th ed.). New York: Duxbury Press.

Karasek, R. (1979). Job demands, job decisions latitude, and mental strain: implications for job redesign. Administrative Science Quarterly, 24, 285-306.

Karasek, R. (1989). Control in the workplace and its health related aspects. In S. Sauter, J. Hurrell, \& C. Cooper (Eds.), Job control and worker health. Chichester, England: Wiley.

LeBlanc, V., MacDonald, R., \& Lepine, T. (2004). Paramedic performance under stress. Air Medical Journal, 23, 5.

LeBlanc, V., MacDonald, R., Russel, D., McArthur, B, King, K., \& Lepine, T. (2005). Paramedic performance in calculating drug dosages following stressful scenarios in a human patient simulator. Prehospital Emergency Care, 9, 439-444.

Marmar, C. R., Weiss, D. S., Metzler, T. J., \& Delucchi, K. (1996). Characteristics of emergency services personnel related to peritraumatic dissociation during critical incident exposure. American Journal of Psychiatry, 153(7), 94-102.

Mason, J. W. (1971). A re-evaluation of the concept of "non-specificity" in stress theory. Journal of Psychiatric Research, 8, 323-333.

Mason, J. W. (1975). A historical view of the stress field: Part 2. Journal of Human Stress, 1, 22-36.

Mitchell, J. T. (1984). The 600 rum limit. Journal of Emergency Medical Services, 8(1), 55-58. 
Mitchell, J. T., \& Bray, G. (1990). Emergency Services Stress. Englewood Cliffs, New Jersey: Prentice Hall.

Mitchell, J. T., \& Everly, G. S. (1995). The critical incident stress debriefing (CISD) and the prevention of work-related traumatic stress among high risk occupational groups. In: G. Everly \& J. Lating (Eds.), Psychotraumatology: Key papers and core concepts in post-traumatic stress. New York: Plenum Press.

Sarason, I. G., Levine, H. M., Basham, R. B., \& Sarason, B. R. (1983). Assessing social support: the social support questionnaire. Journal of Personality and Social Psychology, 44(1), 127-139.

Schwarzer, R. (1994). Optimism, vulnerability, and self-beliefs as health-related cognitions: a systematic overview. Psychology and Health: An International Journal, 9, 161-180.

Selye, H. (1976). The stress of life. New York: McGraw Hill.

Selye, H. (1983). The stress concept: past present and future. In C. L. Cooper (Ed.), Stress research. New York: John Wiley \& Sons.

Wood, G. J. (1989). Stress, social support, and personality of paramedics and emergency medical technicians. Doctoral Dissertation, University of Sourthern California, Los Angeles, California.

Young, K. M., \& Cooper, C. L. (1997). Occupational stress in the ambulance service: a diagnostic study. Health Manpower Management, 23(4-5), 140-147.

\title{
Acknowledgements
}

I would like to thank my dissertation committee. Dr. Walt Stenning has shown patience and leadership in guiding me through my doctoral education. Also, as members of my committee, Dr. Buzz Pruitt, Dr. Larry Dooley, and Dr. Lloyd Korhonen have been a tremendous help with the completion of my education. The time spent editing my work and advising me on a myriad of different issues. I would also like to thank all of the participants from the different emergency medical services utilized in this study. I sincerely hope that these findings contribute to the body of knowledge on stress in EMS and that the field of pre-hospital emergency medicine can eventually benefit from such knowledge. Above all, the one person who has demonstrated the most patience, encouragement, and support was my lovely wife, Laura. Thank you.

\author{
Author Information \\ Roger Bounds, Ph.D., CHES \\ Northern Arizona University \\ Department of Health Sciences \\ PO 15095 \\ Flagstaff, Arizona 86011-5095 \\ Ph. 928-523-6159 \\ E-Mail: Roger.Bounds@nau.edu
}




\section{Appendix A}

Demographic characteristics by job function

\begin{tabular}{|c|c|c|}
\hline Variable Name & Frequency & Percent \\
\hline \multicolumn{3}{|l|}{ Sex } \\
\hline Female & 58 & 40.3 \\
\hline Male & 86 & 59.7 \\
\hline Total & 144 & 100 \\
\hline \multicolumn{3}{|l|}{ Certification } \\
\hline ECA & 2 & 1.4 \\
\hline EMT-B & 15 & 10.4 \\
\hline EMT-I & 12 & 8.3 \\
\hline EMT-P & 70 & 48.6 \\
\hline $\mathrm{LP}$ & 45 & 31.3 \\
\hline Total & 144 & 100 \\
\hline \multicolumn{3}{|l|}{ Job function } \\
\hline Attendant Basic or Int & 23 & 16 \\
\hline Attendant Paramedic & 27 & 18.8 \\
\hline In-Charge Paramedic & 67 & 46.5 \\
\hline Field Supervisor & 13 & 9.0 \\
\hline Other & 14 & 9.7 \\
\hline \begin{tabular}{|l|} 
Total \\
\end{tabular} & 144 & 100 \\
\hline \multicolumn{3}{|l|}{ Marital status } \\
\hline Never Married & 58 & 40.3 \\
\hline Married (first time) & 48 & 33.3 \\
\hline Remarried & 19 & 13.2 \\
\hline Separated or Divorced & 17 & 11.8 \\
\hline Widowed & 1 & 0.7 \\
\hline Missing data & 1 & 0.7 \\
\hline Total & 144 & 100 \\
\hline \multicolumn{3}{|l|}{ Attending school } \\
\hline Yes & 61 & 42.4 \\
\hline No & 83 & 57.6 \\
\hline Total & 144 & 100 \\
\hline
\end{tabular}


Appendix B

Multiple comparisons for job function ANOVA (Fischer’s LSD)

\begin{tabular}{|c|c|c|c|c|c|c|c|}
\hline & & & $\begin{array}{c}\text { Mean } \\
\text { Diff }\end{array}$ & $\begin{array}{l}\text { Std. } \\
\text { Error }\end{array}$ & Sig. & \multicolumn{2}{|c|}{$\begin{array}{l}\text { 95\% Confidence } \\
\text { Interval }\end{array}$} \\
\hline Dep Variable & (I) Job Resp & (J) Job Resp & & & & Lower Bound & Upper Bound \\
\hline \multirow{6}{*}{ SANX } & Attend B-I & Attend Para & 3.8824 & 1.5871 & .016 & .7383 & 7.0266 \\
\hline & & I C Para & 1.0909 & \begin{tabular}{|l|}
1.3517 \\
\end{tabular} & .421 & -1.5869 & 3.7686 \\
\hline & Attend Para & Attend B-I & -3.8824 & 1.5871 & .016 & -7.0266 & -.7383 \\
\hline & & I C Para & -2.7916 & 1.2750 & .031 & -5.3174 & -.2658 \\
\hline & I C Para & Attend B-I & -1.0909 & 1.3517 & .421 & -3.7686 & 1.5869 \\
\hline & & Attend Para & 2.7916 & 1.2750 & .031 & .2658 & 5.3174 \\
\hline & & & & & & & \\
\hline \multirow[t]{7}{*}{ SANG } & Attend B-I & Attend Para & 3.0016 & 1.4809 & .045 & 6.789E-02 & 5.9353 \\
\hline & & I C Para & 2.0370 & 1.2613 & .109 & -.4616 & 4.5356 \\
\hline & Attend Para & Attend B-I & -3.0016 & 1.4809 & .045 & -5.9353 & $-6.7890 \mathrm{E}-02$ \\
\hline & & I C Para & -.9646 & 1.1897 & .419 & -3.3214 & 1.3922 \\
\hline & I C Para & Attend B-I & -2.0370 & 1.2613 & .109 & -4.5356 & .4616 \\
\hline & & Attend Para & .9646 & 1.1897 & .419 & -1.3922 & 3.3214 \\
\hline & & & & & & & \\
\hline \multirow[t]{7}{*}{ SDEP } & Attend B-I & Attend Para & 4.2673 & 1.6148 & .009 & 1.0685 & 7.4661 \\
\hline & & I C Para & 2.0058 & 1.3753 & .147 & -.7186 & 4.7303 \\
\hline & Attend Para & Attend B-I & -4.2673 & 1.6148 & .009 & -7.4661 & -1.0685 \\
\hline & & I C Para & -2.2615 & 1.2972 & .084 & -4.8313 & .3083 \\
\hline & I C Para & Attend B-I & -2.0058 & 1.3753 & .147 & -4.7303 & .7186 \\
\hline & & Attend Para & 2.2615 & 1.2972 & .084 & -.3083 & 4.8313 \\
\hline & & & & & & & \\
\hline \multirow[t]{7}{*}{ TANX } & Attend B-I & Attend Para & 3.9259 & 1.5555 & .013 & .8444 & 7.0074 \\
\hline & & I C Para & 2.4030 & 1.3248 & .072 & -.2215 & 5.0275 \\
\hline & Attend Para & Attend B-I & $\begin{array}{l}-3.9259 \\
\end{array}$ & 1.5555 & .013 & -7.0074 & -.8444 \\
\hline & & I C Para & -1.5229 & 1.2496 & .225 & -3.9985 & .9526 \\
\hline & I C Para & Attend B-I & -2.4030 & 1.3248 & .072 & -5.0275 & .2215 \\
\hline & & Attend Para & 1.5229 & 1.2496 & .225 & -.9526 & 3.9985 \\
\hline & & & & & & & \\
\hline \multirow[t]{6}{*}{ TANG } & Attend B-I & Attend Para & 2.6812 & 1.7918 & .137 & -.8684 & 6.2307 \\
\hline & & I C Para & 1.2732 & 1.5261 & .406 & -1.7499 & 4.2963 \\
\hline & Attend Para & Attend B-I & -2.6812 & \begin{tabular}{|c|}
1.7918 \\
\end{tabular} & .137 & -6.2307 & .8684 \\
\hline & & I C Para & -1.4080 & 1.4395 & .330 & -4.2595 & 1.4436 \\
\hline & I C Para & Attend B-I & -1.2732 & 1.5261 & .406 & -4.2963 & 1.7499 \\
\hline & & Attend Para & 1.4080 & 1.4395 & .330 & -1.4436 & 4.2595 \\
\hline \multirow{7}{*}{ TDEP } & Attend B-I & Attend Para & 4.1804 & 1.7544 & .019 & .7049 & 7.6558 \\
\hline & & I C Para & 1.3816 & \begin{tabular}{|l|}
1.4942 \\
\end{tabular} & . 357 & -1.5785 & 4.3416 \\
\hline & Attend Para & Attend B-I & -4.1804 & 1.7544 & .019 & -7.6558 & -.7049 \\
\hline & & I C Para & \begin{tabular}{|c|}
-2.7988 \\
\end{tabular} & 1.4094 & .049 & -5.5908 & $-6.7408 \mathrm{E}-03$ \\
\hline & I C Para & Attend B-I & -1.3816 & 1.4942 & .357 & -4.3416 & 1.5785 \\
\hline & & Attend Para & 2.7988 & 1.4094 & .049 & $6.741 \mathrm{E}-03$ & 5.5908 \\
\hline & & & & & & & \\
\hline
\end{tabular}

*The mean difference is significant at the .05 level. 


\section{Appendix C}

ANOVA summary table for perception of call volume

\begin{tabular}{|l|l|r|r|r|r|r|}
\hline & & Sum of Squares & df & Mean Square & F & Sig. \\
\hline & & & & & & \\
\hline SANX & Between Groups & 457.547 & 5 & 91.509 & 3.257 & $\mathbf{. 0 0 8}$ \\
\hline & Within Groups & 3877.675 & 138 & 28.099 & & \\
\hline & Total & 4335.222 & 143 & & & \\
\hline & & & & & & \\
\hline SANG & Between Groups & 480.105 & 5 & 96.021 & 4.457 & $\mathbf{. 0 0 1}$ \\
\hline & Within Groups & 2973.332 & 138 & 21.546 & & \\
\hline & Total & 3453.438 & 143 & & & \\
\hline & & & & & & \\
\hline SDEP & Between Groups & 349.465 & 5 & 69.893 & 2.368 & $\mathbf{. 0 4 3}$ \\
\hline & Within Groups & 4073.973 & 138 & 29.522 & & \\
\hline & Total & 4423.438 & 143 & & & \\
\hline & & & & & & \\
\hline TANX & Between Groups & 481.781 & 5 & 96.356 & 3.501 & $\mathbf{. 0 0 5}$ \\
\hline & Within Groups & 3798.191 & 138 & 27.523 & & \\
\hline & Total & 4279.972 & 143 & & & \\
\hline & & & & & & \\
\hline TANG & Between Groups & 962.236 & 5 & 192.447 & 6.066 & $\mathbf{. 0 0 0}$ \\
\hline & Within Groups & 4378.403 & 138 & 31.728 & & \\
\hline & Total & 5340.639 & 143 & & & \\
\hline & & & & & & \\
\hline TDEP & Between Groups & 592.287 & 5 & 118.457 & 3.500 & $\mathbf{. 0 0 5}$ \\
\hline & Within Groups & 4671.150 & 138 & 33.849 & & \\
\hline & Total & 5263.438 & 143 & & & \\
\hline
\end{tabular}

